\title{
Quest for an optimal methane hydrates formation in the pores of hydrolytically stable MOFs
}

Carlos Cuadrado-Collados, Georges Mouchaham, Luke Daemen, Yongqiang Cheng, Anibal Ramirez-Cuesta, Himanshu Aggarwal, Alexander Missyul, Mohamed Eddaoudi, Youssef Belmabkhout and Joaquin Silvestre-Albero.

\section{Supporting Information}

\section{Content}

\section{$\underline{\text { Experimental details }}$}

- Synthesis and characterization of MOFs

- High-pressure adsorption isotherms

- Inelastic neutrons scattering (INS) measurements

- Inelastic neutron scattering (INS) modelling

- Synchrotron X-ray powder diffraction measurements

\section{$\underline{\text { Figures }}$}

Figure S1. PXRD patterns of Y-shp-MOF-5 calculated and experimental (freshly prepared sample).

Figure S2. Nitrogen adsorption (solid spheres) and desorption (empty circles) isotherms measured at $77 \mathrm{~K}$ on freshly activated Y-shp-MOF-5.

Figure S3. Water adsorption (solid spheres) and desorption (empty circles) isotherms measured at $298 \mathrm{~K}$ for activated sample of Y-shp-MOF-5. The acetone-exchanged Y-shp-MOF-5 sample was activated at $398 \mathrm{~K}$ before the sorption experiment for $8 \mathrm{~h}$. The maximum equilibrium time for each $\mathrm{RH}$ was maintained at $1 \mathrm{~h}$.

Figure S4. PXRD patterns of Cr-soc-MOF-1 calculated and experimental (freshly prepared sample).

Figure S5. Nitrogen adsorption (solid spheres) and desorption (empty circles) isotherms measured at $77 \mathrm{~K}$ on freshly activated Cr-soc-MOF-1.

Figure S6. Water adsorption (solid spheres) and desorption (empty circles) isotherms measured at $298 \mathrm{~K}$ for activated sample of Cr-soc-MOF-1. The acetone-exchanged Cr-soc-MOF-1 sample was 
activated at $393 \mathrm{~K}$ before the sorption experiment for $8 \mathrm{~h}$. The maximum equilibrium time for each $\mathrm{RH}$ was maintained at $1 \mathrm{~h}$.

Figure S7. INS spectra of Y-shp-MOF-1 at $5 \mathrm{~K}$ in the (a) low and (b) mid-energy region.

Figure S8. INS spectra of Cr-soc-MOF-1 at $5 \mathrm{~K}$ in the (a) low and (b) mid-energy region.

Figure S9. INS spectra at $5 \mathrm{~K}$ for Y-shp-MOF-5 in the (a) low and (b) mid-energy transfer regions for the original, $\mathrm{D}_{2} \mathrm{O}$-loaded (up to saturation), $\mathrm{CH}_{4}$-loaded (6.0 MPa, physisorbed methane) and $\mathrm{D}_{2} \mathrm{O}+\mathrm{CH}_{4}$ loaded system (deuterated water saturation and 6.0 $\mathrm{MPa} \mathrm{CH}_{4}$ ).

Figure S10. INS spectra at $5 \mathrm{~K}$ for Cr-soc-MOF-1 in the (a) low and (b) mid-energy transfer regions for the original, $\mathrm{D}_{2} \mathrm{O}$-loaded (up to saturation), $\mathrm{CH}_{4}$-loaded (6.0 MPa, physisorbed methane) and $\mathrm{D}_{2} \mathrm{O}+\mathrm{CH}_{4}$ loaded system (deuterated water saturation and 6.0 $\mathrm{MPa} \mathrm{CH}_{4}$ ).

Figure S11. Phase diagram for methane hydrate (a) nucleation and (b) dissociation in confined nanospace. Bulk hydrate data and methane hydrate data in different carbon materials from the literature $\left(\mathrm{C}_{\text {micro }}\right.$ and $\mathrm{C}_{\text {meso-1 }}$ from ref. [1], and PPAC from ref. [2]) are included for the sake of comparison. 


\section{Experimental details}

\section{- Synthesis and characterization of MOFs}

\section{$\underline{\text { Y-shp-MOF-5 }}$}

$300 \mathrm{mg}$ of Y-shp-MOF-5 have been prepared according to the reported procedure. ${ }^{3}$ A solution $(0.5 \mathrm{~mL})$ of $0.068 \mathrm{M} \mathrm{Y}\left(\mathrm{NO}_{3}\right)_{3} 6 \mathrm{H}_{2} \mathrm{O}$ in DMF was added to a solution of the organic ligand ((1,2,4,5-tetrakis(4-carboxyphenyl)benzene $\left(\mathrm{H}_{4}\right.$-BTEB); $\left.6.7 \mathrm{mg}, 0.012 \mathrm{mmol}\right)$ in $0.5 \mathrm{~mL}$ of DMF already contained in $20 \mathrm{~mL}$ scintillation vial. To this mixture, $2.01 \mathrm{~mL}$ of $4 \mathrm{M} 2$-fluorobenzoic acid $(8.04 \mathrm{mmol})$ in DMF and $0.75 \mathrm{~mL}$ of $\mathrm{H}_{2} \mathrm{O}$ were added before sealed the vial and placing it into a pre-heated oven at $378 \mathrm{~K}$ for $24 \mathrm{~h}$. The vial was then removed and colorless hexagonal bipyramidal crystals were harvested, thoroughly washed with DMF and finally with acetone prior to further studies.

\section{$\underline{\text { Cr-soc-MOF-1 }}$}

$300 \mathrm{mg}$ of Cr-soc-MOF-1 have been prepared according to the reported procedure. ${ }^{4} \mathrm{Fe}-$-soc-MOF$1(50 \mathrm{mg})$ crystals were quickly washed with acetonitrile and acetone before being transferred to an inert atmosphere glove box. A solution of $\mathrm{CrCl}_{2}(300 \mathrm{mg})$ in DMF $(6 \mathrm{~mL})$ was then carefully added into a scintillation vial containing the Fe-soc-MOF-1. The capped vial was taken out of the glovebox and incubated at $388 \mathrm{~K}$ for $20 \mathrm{~h}$. After cooling down to room temperature, the dark-green supernatant solution was removed, and the resulting green crystals of $\mathrm{Cr}$-soc-MOF-1 were thoroughly washed with DMF and acetone prior to be used for different studies.

\section{- Powder X-ray diffraction (PXRD) measurements}

PXRD measurements were performed on a PANalytical MPD X'Pert PRO X-ray diffractometer at $45 \mathrm{kV}$ and $40 \mathrm{~mA}$ for $\mathrm{Cu} \mathrm{K \alpha}(\lambda=1.5418 \AA, 45 \mathrm{kV}$ and $40 \mathrm{~mA})$.

\section{- Low-pressure gas $\mathbf{N}_{2}$ sorption studies}

Textural characterization of the synthesized MOFs was conducted in a fully automated surface area and micropore gas analyzer Quadrasorb (Quantachrome Instruments) at relative pressures up to $1 \mathrm{~atm}$. The temperature was controlled using liquid $\mathrm{N}_{2}$ bath.

\section{- Water sorption experiments}

Water adsorption/desorption isotherms were measured with a VTI-SA vapor sorption analyzer from TA instruments (New Castle, DE, United States). The water vapor activity was controlled automatically by mixing wet vapor feed with a dry $\mathrm{N}_{2}$ line (carrier gas). The sample "dry mass" was measured under $\mathrm{N}_{2}$ and at equilibrium before water vapor was introduced into the chamber. The adsorption isotherms, obtained at equilibrium, were collected within a range of $0 \%-90 \% \mathrm{RH}$.

\section{- High-pressure adsorption isotherms}

High-pressure methane adsorption/desorption measurements were performed in a home-built manometric equipment. Before the adsorption measurements, samples were degassed at $413 \mathrm{~K}$ for 24h. To grow the hydrates, MOF samples were pre-loaded with $\mathrm{H}_{2} \mathrm{O}$ at different ratios $\left(\mathrm{R}_{\mathrm{w}}=\right.$ $0.3,0.5$ and 0.75 , for shp-MOF-5 and $\mathrm{R}_{\mathrm{w}}=0.5,2,3$ and 4, for Cr-soc-MOF; $\mathrm{R}_{\mathrm{w}}$ represents the mass of water to dry MOF). Undersaturated and saturated samples were prepared by placing the outgassed MOFs in a humidity controlled chamber until the corresponding weight increase was reached. In the specific case of the oversaturated samples, the saturated samples were further impregnated with additional water using a calibrated syringe until the desired water loading was 
reached. High-pressure isotherms were performed at $275 \mathrm{~K}$ and up to $10.0 \mathrm{MPa}$. Before the highpressure measurements, the pre-humidified samples were frozen at $253 \mathrm{~K}$ before applying the vacuum in the adsorption equipment to avoid water losses.

\section{- Inelastic neutron scattering (INS) measurements}

Inelastic neutron scattering (INS) measurements were performed at the VISION beamline (BL16B) of the Spallation Neutron Source (SNS), Oak Ridge National Laboratory (ORNL), USA. About $200 \mathrm{mg}$ of MOF was loaded in an Al sample holder connected to a gas handling system. The blank samples were first evacuated for $24 \mathrm{~h}$ at $413 \mathrm{~K}$ and subsequently cooled down to $5 \mathrm{~K}$. Once at this temperature, the INS spectrum was collected for several hours (the background for the instrument and sample holder was subtracted from the final spectrum). After the bare MOFs were measured, the samples were loaded with $\mathrm{D}_{2} \mathrm{O}$ until saturation and pressurized with $\mathrm{CH}_{4}$ up to $6.0 \mathrm{MPa}$. After $1 \mathrm{~h}$ at this pressure, the sample holder was cooled down to $5 \mathrm{~K}$ to evaluate the potential formation of confined hydrate crystals.

\section{- Inelastic neutron scattering (INS) modelling}

Vibrational frequencies and polarization vectors were calculated using $\mathrm{CP} 2 \mathrm{~K}$ (http://www.cp2k.org) ${ }^{5}$, based on the mixed Gaussian and plane-wave scheme ${ }^{6}$ and the Quickstep module. ${ }^{7}$ The calculation used molecularly optimized Double-Zeta-Valence plus Polarization (DZVP) basis set, ${ }^{8}$ Goedecker-Teter-Hutter pseudopotentials, ${ }^{9}$ and the Perdew-Burke-Ernzerhof (PBE) exchange correlation functional. ${ }^{10}$ The plane-wave energy cutoff was $400 \mathrm{Ry}$. The calculation was performed on Gamma point only, with no symmetry constraint. Structural optimization was performed using the Broyden-Fletcher-Goldfarb-Shannon (BFGS) optimizer, until the maximum force is below $0.00045 \mathrm{Ry} / \mathrm{Bohr}(0.011 \mathrm{eV} / \AA \AA$ ). Finite displacement method was used for the phonon calculation, with incremental displacement of $0.01 \operatorname{Bohr}(0.0053 \AA)$. The INS spectrum was then simulated using the OClimax software. ${ }^{11}$

\section{- Synchrotron X-ray powder diffraction measurements (SXRPD)}

The in situ synchrotron X-ray powder diffraction data were collected at the MSPD beamline at the ALBA synchrotron (Cerdanyola del Vallès, Spain). ${ }^{12}$ The measurements were performed at $30 \mathrm{keV}$ photon energy (wavelength 0.4135 Å refined using NIST 640e standard) using MYTHEN position sensitive detector. Sample temperature was controlled by Oxford Cryosystems 700 Series Cryostream cooling device and a home-made capillary flow cell was employed to control the gas pressure.

Rietveld refinement was made using GSAS package ${ }^{13}$ with EXPGUI interface. ${ }^{14}$ Taking into account limited amount of data available under in situ conditions, only lattice parameters, overall Debye-Waller factor and occupancy of the water sites were refined with respect to the known structure. ${ }^{15}$ 


\section{Figures}

\section{$\underline{\text { Y-shp-MOF-5 }}$}

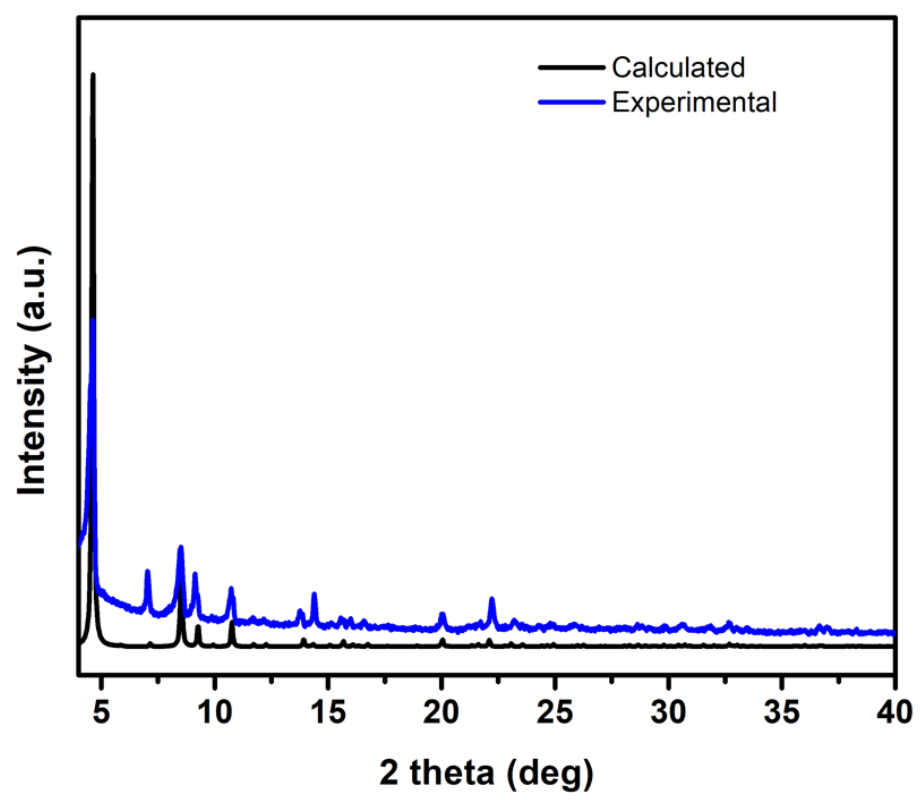

Figure S1. PXRD patterns of Y-shp-MOF-5 calculated and experimental (freshly prepared sample).

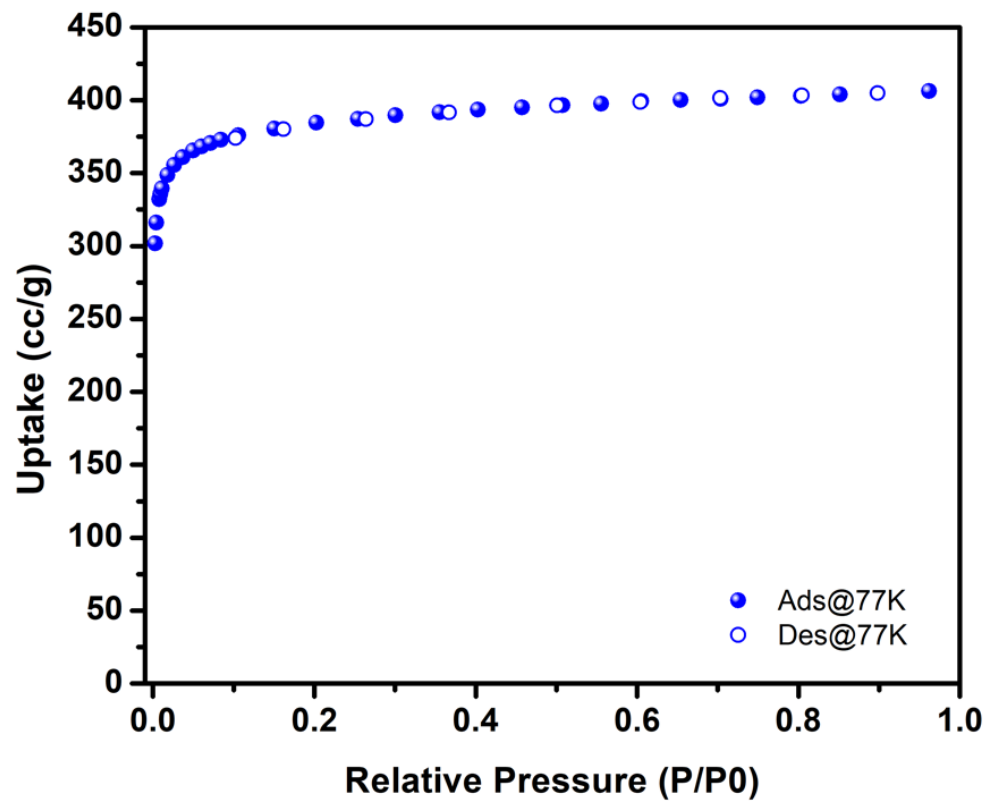

Figure S2. Nitrogen adsorption (solid spheres) and desorption (empty circles) isotherms measured at $77 \mathrm{~K}$ on freshly activated Y-shp-MOF-5. 


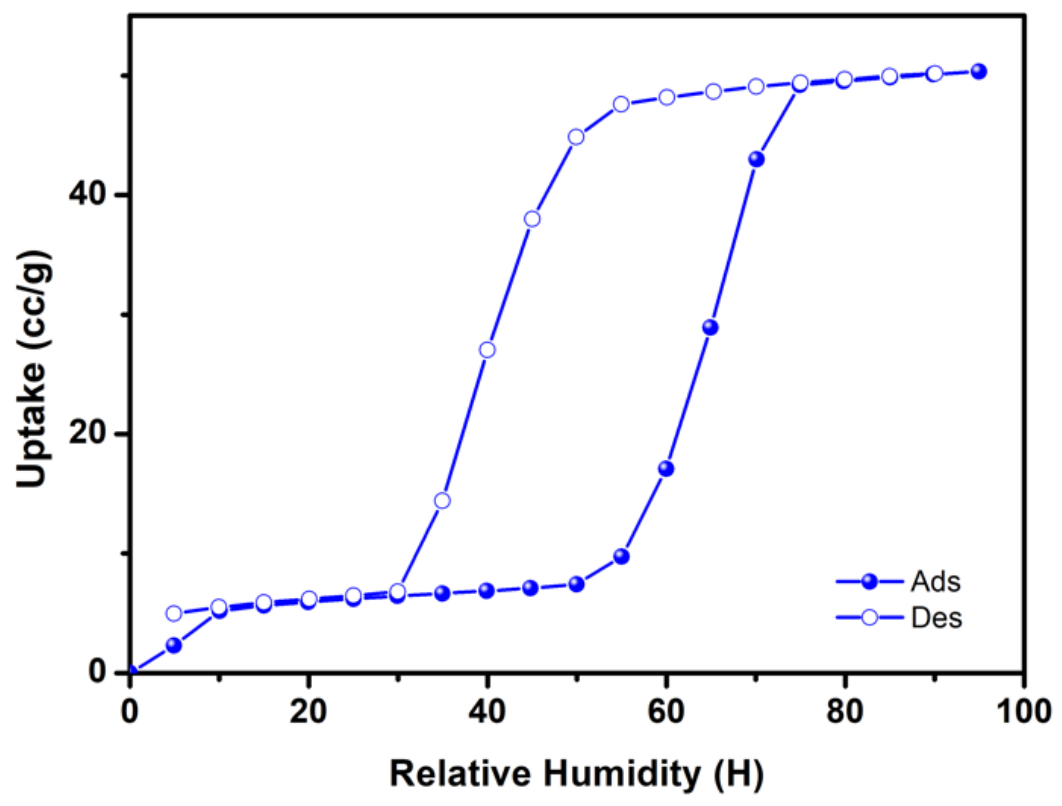

Figure S3. Water adsorption (solid spheres) and desorption (empty circles) isotherms measured at 298 $\mathrm{K}$ for activated sample of Y-shp-MOF-5. The acetone-exchanged Y-shp-MOF-5 sample was activated at $398 \mathrm{~K}$ before the sorption experiment for $8 \mathrm{~h}$. The maximum equilibrium time for each $\mathrm{RH}$ was maintained at $1 \mathrm{~h}$. 


\section{Cr-soc-MOF-1}

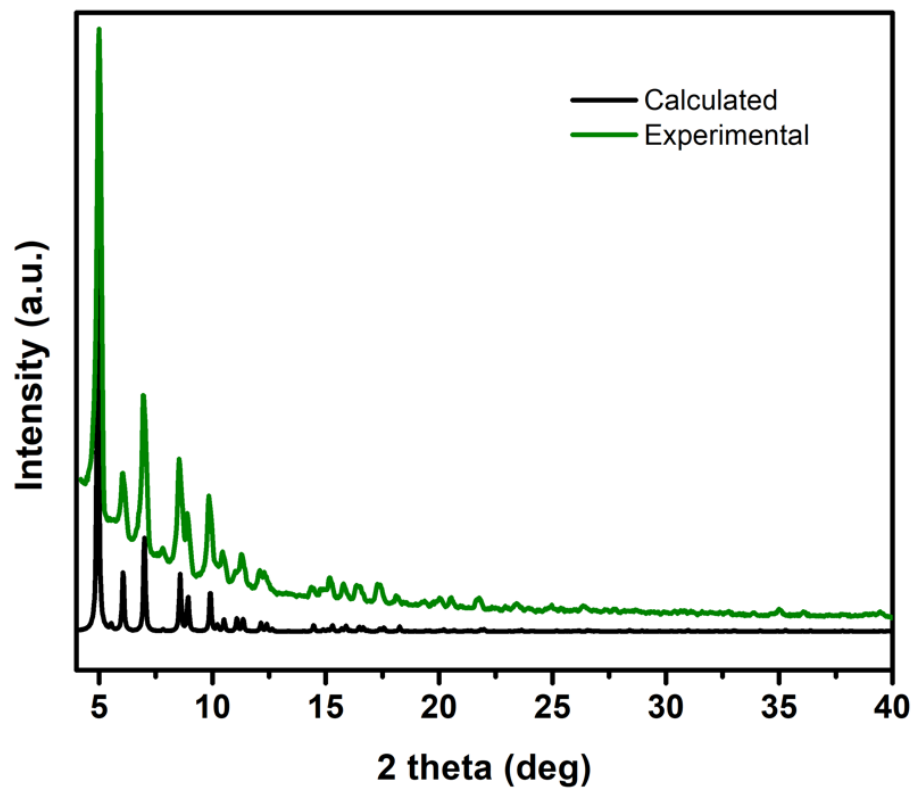

Figure S4. PXRD patterns of Cr-soc-MOF-1 calculated and experimental (freshly prepared sample).

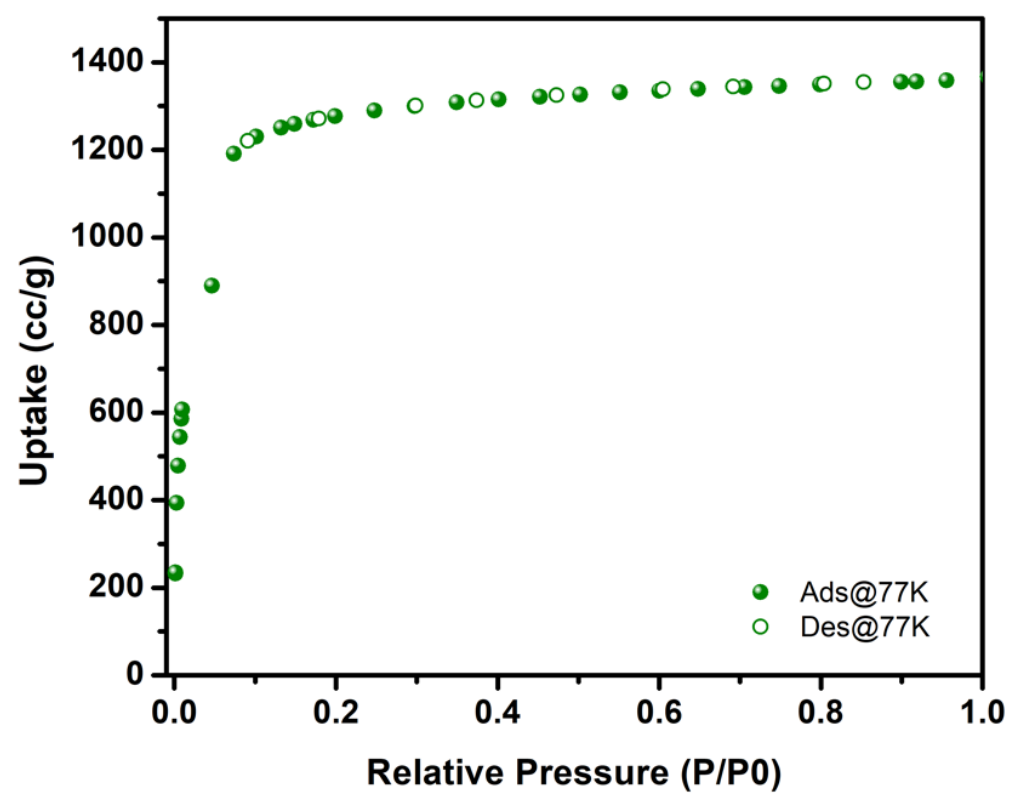

Figure S5. Nitrogen adsorption (solid spheres) and desorption (empty circles) isotherms measured at $77 \mathrm{~K}$ on freshly activated Cr-soc-MOF-1. 


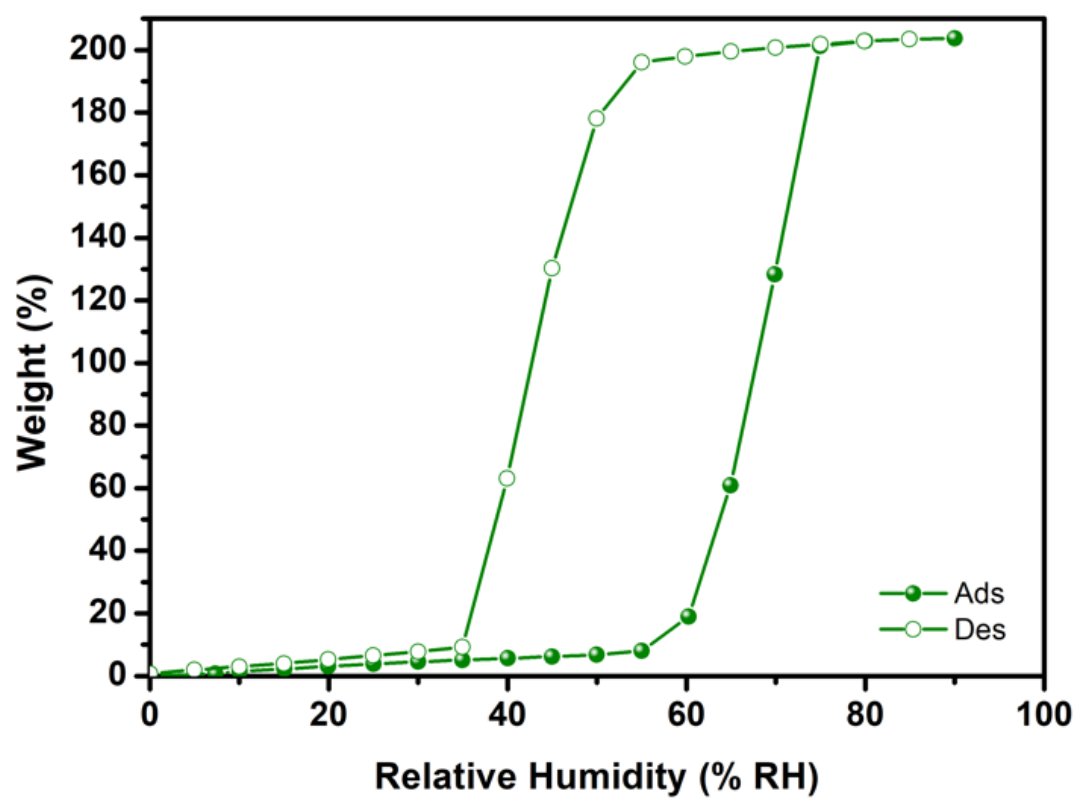

Figure S6. Water adsorption (solid spheres) and desorption (empty circles) isotherms measured at 298 $\mathrm{K}$ for activated sample of Cr-soc-MOF-1. The acetone-exchanged Cr-soc-MOF-1 sample was activated at $393 \mathrm{~K}$ before the sorption experiment for $8 \mathrm{~h}$. The maximum equilibrium time for each $\mathrm{RH}$ was maintained at $1 \mathrm{~h}$. 


\section{$\underline{\text { Inelastic neutron scattering (INS) }}$}
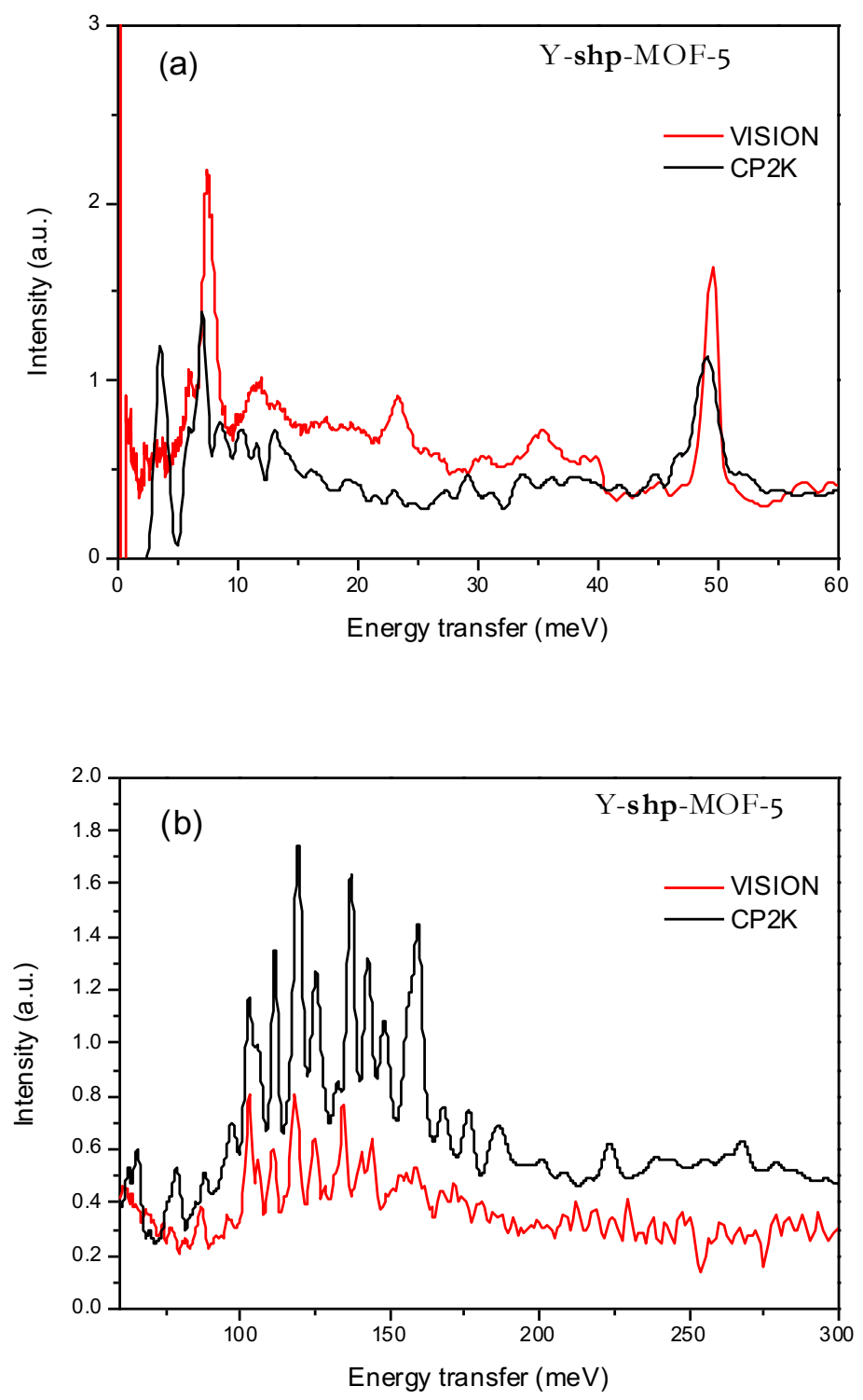

Figure S7. INS spectra of Y-shp-MOF-5 at $5 \mathrm{~K}$ in the (a) low and (b) mid-energy region. 

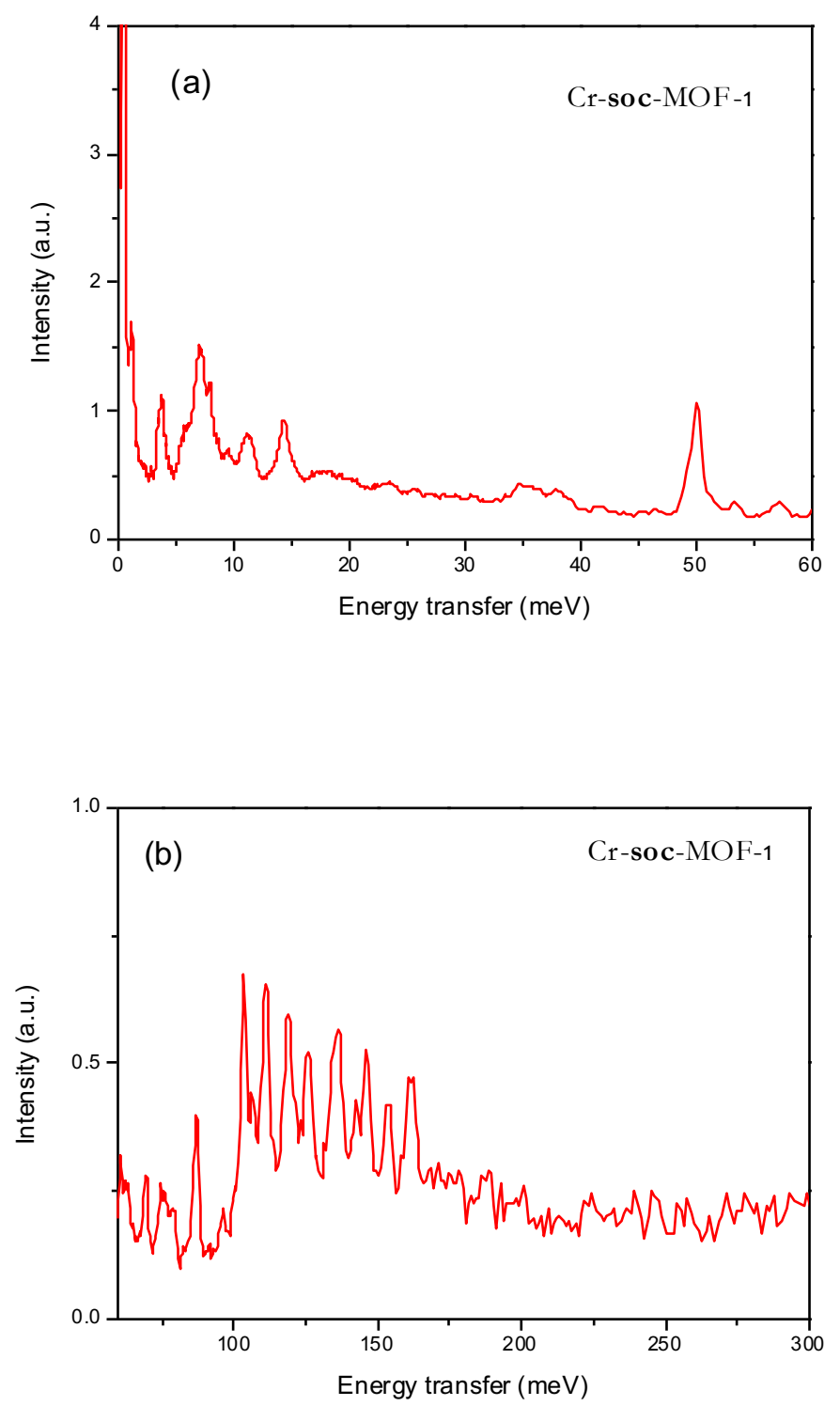

Figure S8. INS spectra of Cr-soc-MOF-1 at $5 \mathrm{~K}$ in the (a) low and (b) mid-energy region. 

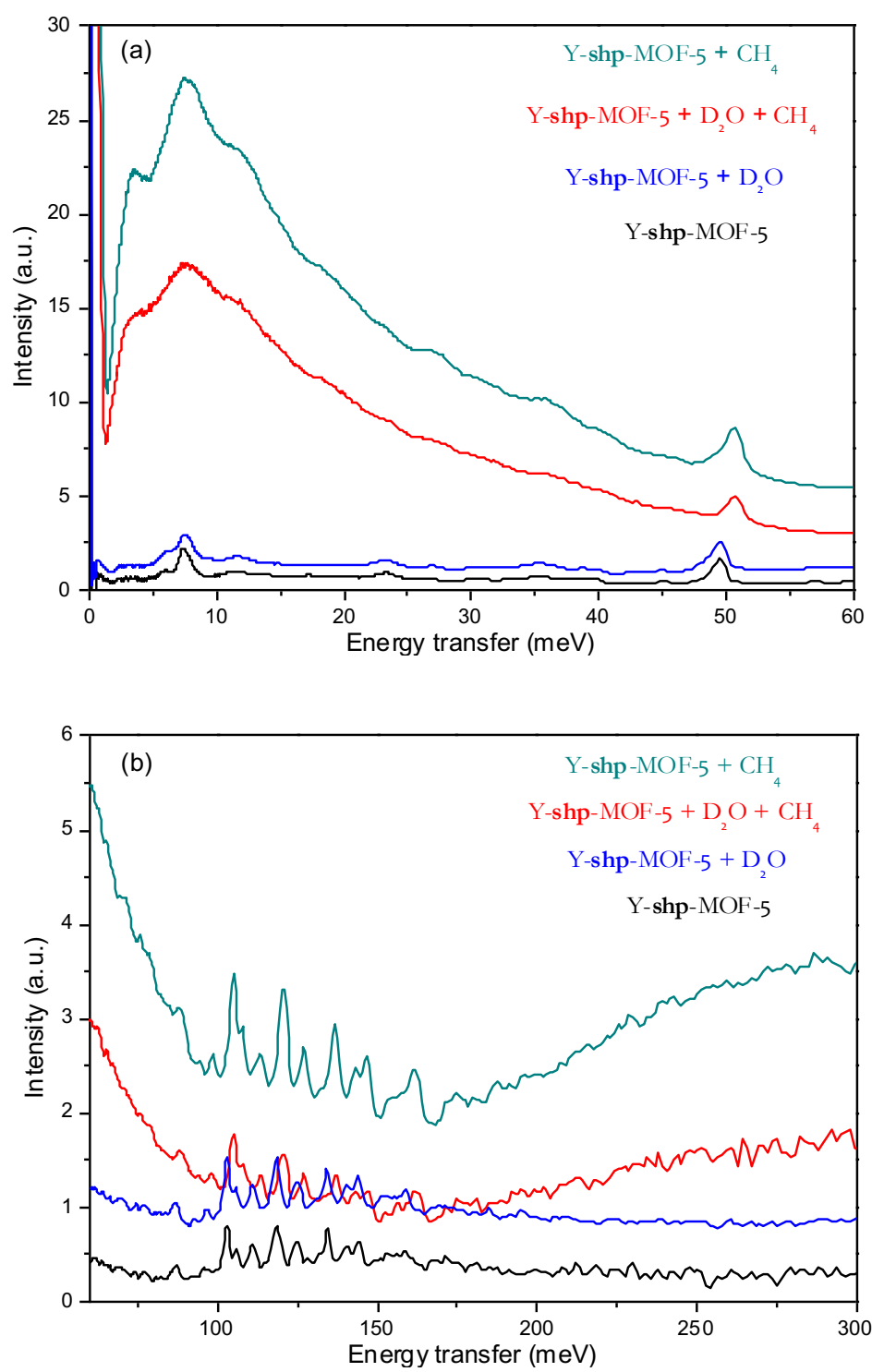

Figure S9. INS spectra at $5 \mathrm{~K}$ for Y-shp-MOF-5 in the (a) low and (b) mid-energy transfer regions for the original, $\mathrm{D}_{2} \mathrm{O}$-loaded (up to saturation), $\mathrm{CH}_{4}$-loaded (6.0 MPa, physisorbed methane) and $\mathrm{D}_{2} \mathrm{O}+\mathrm{CH}_{4}$ loaded system (deuterated water saturation and 6.0 $\mathrm{MPa} \mathrm{CH}_{4}$ ). 

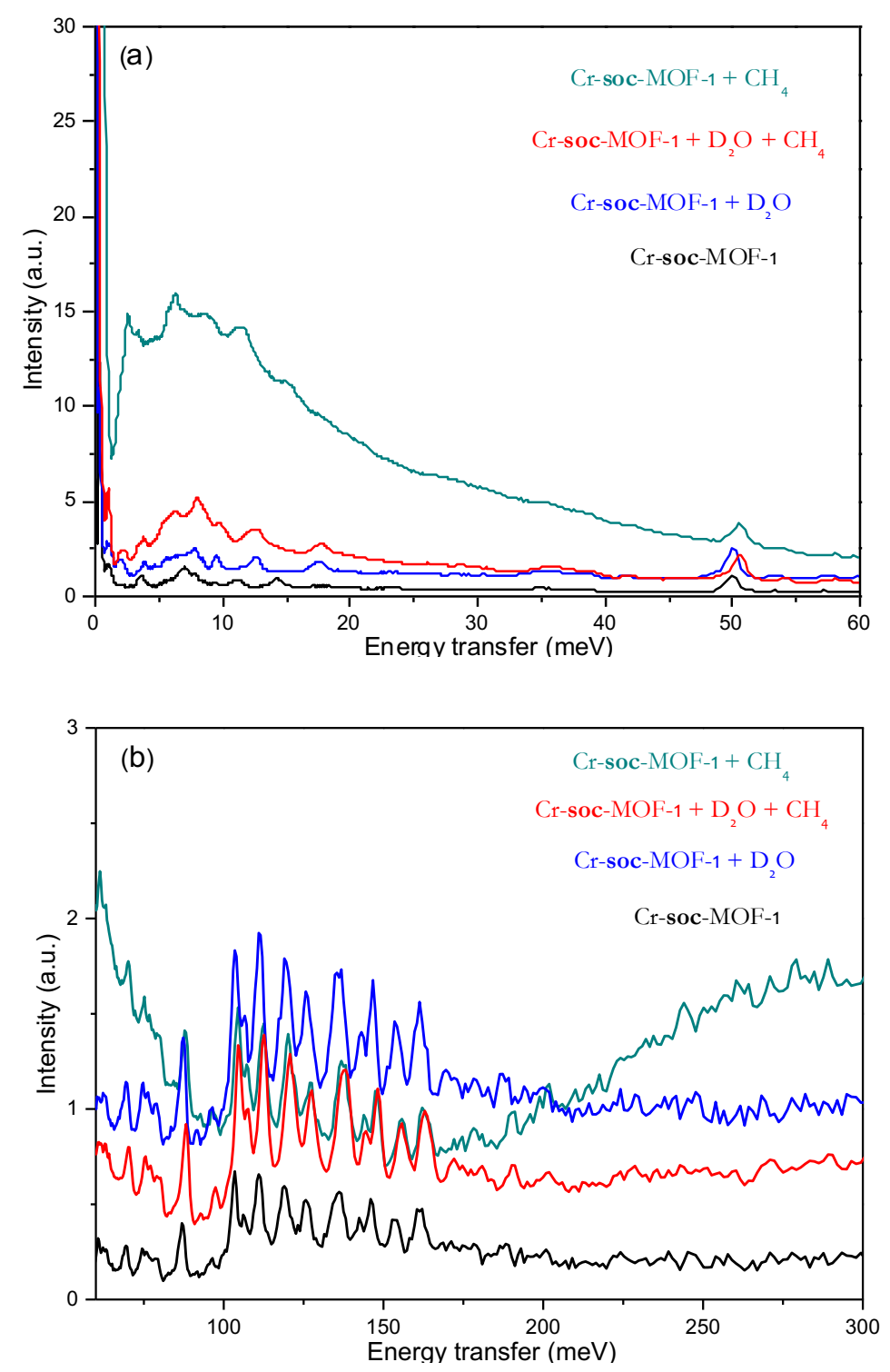

Figure S10. INS spectra at $5 \mathrm{~K}$ for Cr-soc-MOF-1 in the (a) low and (b) mid-energy transfer regions for the original, $\mathrm{D}_{2} \mathrm{O}$-loaded (up to saturation), $\mathrm{CH}_{4}$-loaded (6.0 MPa, physisorbed methane) and $\mathrm{D}_{2} \mathrm{O}$ $+\mathrm{CH}_{4}$ loaded system (deuterated water saturation and $6.0 \mathrm{MPa} \mathrm{CH}_{4}$ ). 


\section{Phase diagram}
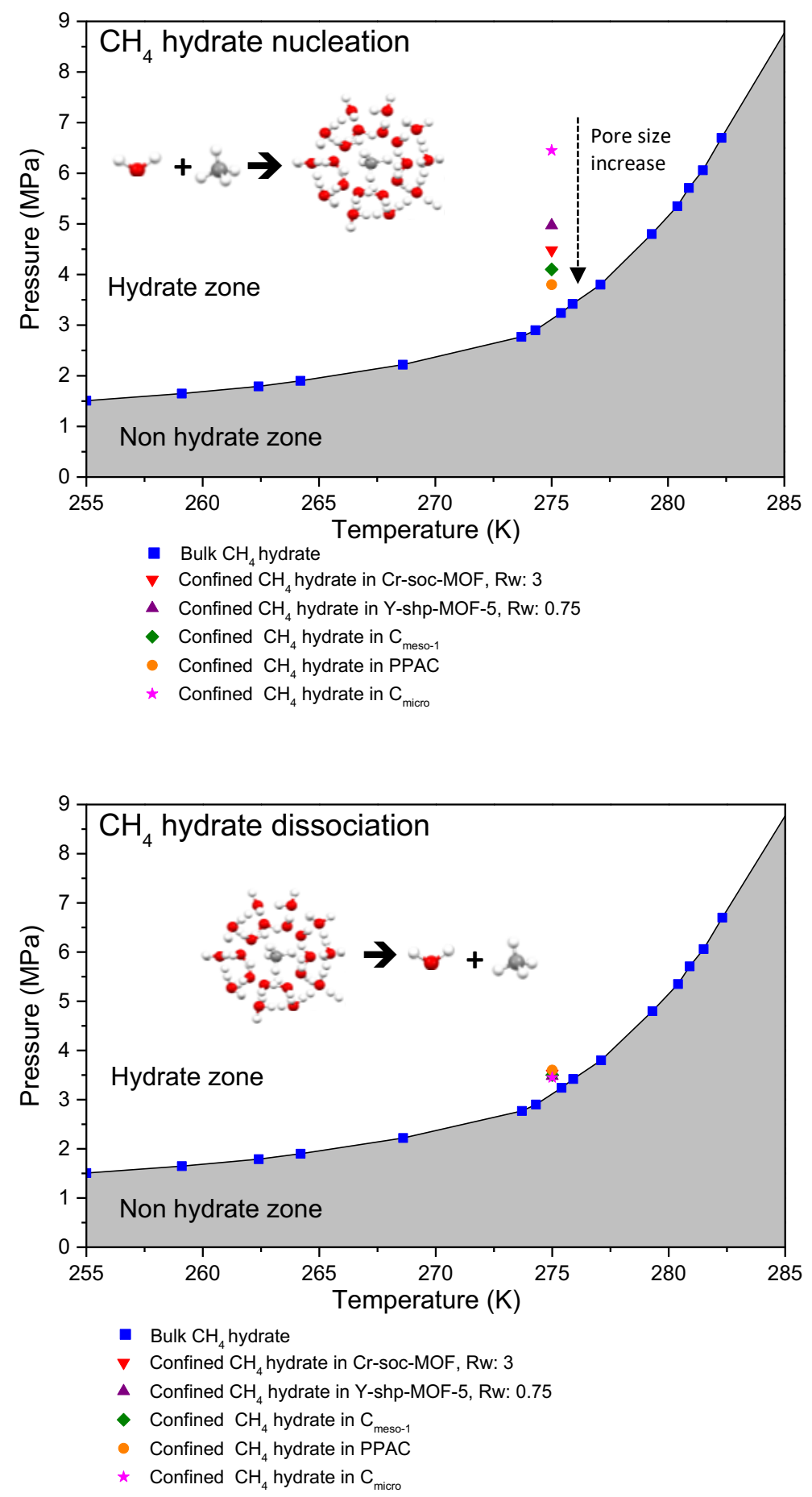

Figure S11. Phase diagram for methane hydrate (a) nucleation and (b) dissociation in confined nanospace. Bulk hydrate data and methane hydrate data in different carbon materials from the literature $\left(\mathrm{C}_{\text {micro }}\right.$ and $\mathrm{C}_{\text {meso-1 }}$ from ref. [1], and PPAC from ref. [2]) are included for the sake of comparison. 


\section{References}

(1) Borchardt, L.; Nickel, W.; Casco, M.; Senkovska, I.; Bon, V.; Wallacher, D.; Grimm, N.; Krause, S.; Silvestre-Albero, J., Phys. Chem. Chem. Phys. 2016, 18, 20607-20614.

(2) Casco, M.E.; Silvestre-Albero, J.; Ramirez-Cuesta, A.J.; Rey, F.; Jordá, J.L.; Bansode, A.; Urakawa, A.; Peral, I.; Martínez-Escandell, M.; Kaneko, K.; Rodríguez-Reinoso, F., Nature Commun. 2015, 6, 6432 .

(3) AbdulHalim, R.G.; Bhatt, P.M.; Belmabkhout, Y.; Shkurenko, A.; Adil, K.; Barbour, L.J.; Eddaoudi, M., J. Am. Chem. Soc., 2017, 139, 10715-10722.

(4) Abtab, S.M.T.; Alezi, D.; Bhatt, P.M.; Shkurenko, A.; Belmabkhout, Y.; Aggarwal, H.; Weselinski, L.J.; Alsadun, N.; Samin, U.; Hedhili, M.N.; Eddaoudi, M., Chem, 2018, 4, 94-105.

(5) Hutter, J.; Iannuzzi, M.; Schiffmann, F.; Van de Vondole, J., J. Wiley Interdisciplinary Reviews-Computational Molecular Science, 2014, 4, 15-25.

(6) Lippert, G.; Hutter, J.; Parrinello, M.A., Mol. Phys. 1997, 92, 477-487.

(7) Van de Vondole, J.; et al., Comput. Phys. Commun., 2005, 167, 103-128.

(8) Van de Vondole, J.; Hutter, J., J. Chem. Phys., 2007, 127, 114105.

(9) Goedecker, S.; Teter, M.; Hutter, J., J. Phys. Rev. B, 1996, 54, 1703-1710.

(10) Perdew, J.P.; Burke, K.; Ernzerhof, M., Phys. Rev. Lett., 1996, 77, 3865-3868.

(11) Cheng, Y.Q.; Daemen, L.L.; Kolesnikov, A.I.; Ramirez-Cuesta, A.J., J. Chem. Theory \& Comput., 2019, 15, 1974-1982.

(12) Fauth, F.; Peral, I.; Popescu, C.; Knapp, M., Powder Diffraction, 2013, 28, S360-S370.

(13) Larson, A.C.; Von Dreele, R.B., "General Structure Analysis System (GSAS) (Report LAUR

86-748), Los Alamos National Laboratory, Los Alamos, New Mexico, 2014.

(14) Toby, B.H., J. Appl. Cryst., 2001, 34, 210-213.

(15) Towsif Abtab, S.M.; Alezi, D.; Bhatt, P.M.; Shkurenko, A.; Belmabkhout, Y.; Aggarwal, H.; Weselinski, L.J. et al., Chem, 2018, 4, 94-105. 